\title{
Mídia, educação e democracia: diálogos e desafios em tempos de crise
}

\section{Media, education and democracy: dialogues and challenges in crisis times}

\section{Carla BAIENSE ${ }^{1}$ e Gabriela BORGES ${ }^{2}$}

Os estudos sobre mídia e educação têm início nos anos 1980 a partir das iniciativas da Unesco, em especial a Declaração de Grunwald, escrita durante o International Symposium on Media Education, realizado em 1982 na República Federal da Alemanha, quando se reconheceu o impacto das mensagens midiáticas na sociedade e a importância da educação para as mídias. Desde então, o foco tem sido no estímulo às ações de formação que capacitem os sujeitos a compreenderem criticamente as mensagens midiáticas que recebem no dia a dia. Com o desenvolvimento da tecnologia e o crescimento da cultura participativa no início do século XXI, todo o esforço empreendido pelo campo da mídia-educação está relacionado com o empoderamento dos cidadãos. É importante que percebam de modo crítico as mensagens que recebem, refletindo sobre a circulação e o compartilhamento de conteúdos que têm impactos sociais e culturais; mas também compreendam como este consumo se reflete na produção criativa de mensagens textuais, imagéticas e audiovisuais que constantemente veiculam e compartilham em sites, blogs e redes sociais digitais.

A importância da educação para e pelas mídias está assim relacionada com o exercício da cidadania, no sentido em que os cidadãos, ao estarem bem informados, saberem distinguir a veracidade das notícias que recebem, acessarem sites e conteúdos fidedignos e/ou saberem gerir a sua privacidade online poderão atuar e intervir ativamente na sociedade em que vivem. Ao estar alfabetizado midiaticamente, o sujeito

\footnotetext{
${ }^{1}$ Professora do Programa de Pós-Graduação em Mídia e Cotidiano da Universidade Federal Fluminense. E-mail: carlabaienses@yahoo.com.br

2 Professora do Programa de Pós-Graduação em Comunicação da Universidade Federal de Juiz de Fora. Email: gabriela.borges@ufjf.edu.br
} 


\section{miDiA

poderá contribuir na construção de uma sociedade mais justa e democrática, que respeita a diferença.

Em tempos de crise do capitalismo, em que os estados democráticos estão sendo colocados à prova e os governos autoritários estão crescendo em diferentes partes do mundo, a promoção da literacia midiática (media literacy) é essencial para que os cidadãos possam compreender os diferentes vieses ideológicos das mensagens que recebem; a força e o potencial das campanhas de desinformação e o usufruto do direito à liberdade de expressão e informação a fim de que possam ser consumidores sensatos e produtores de informação acurada. Porém, os desafios são muitos, uma vez que o volume de informação que circula é vertiginoso e o processo de ensino-aprendizagem muitas vezes não consegue acompanhar a velocidade da produção e disseminação dos conteúdos pelas mídias contemporâneas.

Para refletir sobre os desafios e os diálogos possíveis entre mídia, educação e democracia, este dossiê traz experiências de trabalhos realizados no terreno, em escolas e outros espaços, além de reflexões sobre produções midiáticas na internet e uma proposta de desenvolvimento de política pública nesta área.

Abrimos o dossiê com o artigo "Análise crítica de produtos midiáticos: experiência de extensão universitária em escolas públicas de Porto Alegre", em que os pesquisadores Ana Javes Luz, Bruno Garcia, Nicole Morás, Isaura Mourão e Jean Felipe Rossato compartilham a experiência do Grupo de Pesquisa em Comunicação Organizacional, Cultura e Relações de Poder (GCCOP/UFGRS) no desenvolvimento de oficinas junto a jovens e adolescentes do Ensino Médio da cidade. A partir do relato, os autores produzem uma reflexão a respeito do papel da extensão universitáia na construção de processos de análise que contemplem as gramáticas, enquadramentos e representações midiáticas e sua relação com a construção da realidade social.

Fora da escola, mas ainda entre os jovens, Luciana Oliveira e Júlio Figueroa discorrem no artigo "Geradores sensíveis, relações interpessoais e democracia: experiências de cinema com adolescentes no sistema socioeducativo" sobre como o dispositivo possibilita outras formas de enunciação para os que foram colocados à margem da sociedade. Guiados pela noção dialógica de Paulo Freire (2003; 2008), os autores revelam sua experiência com a utilização de rodas de conversas e exercícios 


\section{míDiA \\ eCC \\ DiAno}

audiovisuais como formas de socioeducar os jovens que caíram na malha do sistema judicial.

Considerando a criação do campo jornalístico-midiático em Língua Portuguesa da nova Base Nacional Curricular Comum (BNCC), o artigo "Saberes necessários da educação midiática na era da desinformação", das autoras Egle Müller Spinelli e Jéssica de Almeida Santos, propõe uma reflexão sobre os desafios que o país enfrentará para garantir o desenvolvimento destas competências entre os estudantes. Traz, ainda, uma análise das estratégias adotadas em Portugal como parâmetro para desenvolvimento de políticas públicas nesta área.

Mônica Chaves e Luísa Melo seguem discutindo o papel da alfabetização ou educação midiática num cenârio de desordem da informação. O Artigo "Educação midiática para notícias: histórico e mapeamento de iniciativas para combater a desinformação por meio da educação" recupera, ainda, as iniciativas desenvolvidas nos últimos 90 anos, nos Estados Unidos, e um breve mapeamento de ações feitas no Brasil neste sentido. Por fim, apresenta os principais achados de uma pesquisa tipo survey realizada com professores/as de educação básica no país.

A onda de desinformação e a perda de antigas referências narrativas estão presentes no artigo "Crise epistemológica e teorias da conspiração: o discurso anticiência do canal 'Professor Terra Plana'". Afonso de Albuquerque e Rodrigo Quinan analisam, a partir da plataforma YouTube, a visibilidade que teorias conspiratórias adquirem dentro do atual cenário midiático. Para além do desafio inédito que se apresenta à sociedade, de modo geral e, à universidade, em particular, os pesquisadores chamam atenção para a relação que a popularidade de tais teorias tem com uma crise epistemológica mais ampla, que abala os alicerces institucionais e ameaça a democracia.

As possibilidades de utilização do audiodocumentário para uma educação emancipadora é o tema do artigo de João Djane Assunção da Silva e Nilvania dos Santos Silva. "Produção de audiodocumentário em práticas de educação pela comunicação: empoderamento comunicativo e responsabilidade social" defende que as características do formato podem favorecer os processos de ensino e aprendizagem por meio de uma interação sensorial, ao mesmo tempo em que oferecem possibilidades para o engajamento de grupos minoritários e/ou marginalizados. 


\section{míDiA

O empoderamento de grupos subalternatizados também perpassa as discussões de Márcia Neme Buzalaf, no artigo "Contos à margem: letramentos de sobrevivência e midiativismo nas favelas do Rio de Janeiro". A partir da premissa de que as narrativas da mídia mainstream legitimam a violência contra os moradores de favelas, a autora vai refletir sobre como a apropriação das redes sociais por estes mesmos moradores se constitui como estratégia de sobrevivência em seus territórios.

Já a Seção Livre desta edição da Revista Mídia e Cotidiano, a última de 2019, inicia com o artigo "Excesso e positividade na constituição do sujeito: uma reflexão sobre aplicativos de relacionamento", que discute algumas formas da constituição do sujeito contemporâneo, a partir de uma perspectiva psicoanalítica. A abordagem desdobra-se com o foco no Tinder, um dos aplicativos mais acessados no momento, por quem busca relacionamentos amorosos. $\mathrm{O}$ recorte, que implica em uma breve análise qualitativa dos perfis que acionam este aplicativo, incorpora o diagnóstico do excesso de ofertas e informações atuais sobre o sujeito, em um cenário, portanto, altamente midiatizado, o que, na visão dos autores Eliane Righi de Andrade e Tarcisio Torres Silva, precisa ser considerado quando se investiga a constituição psíquica do sujeito na contemporaneidade.

No artigo seguinte, de autoria de Leonel Azevedo de Aguiar e Luciana de Alcantara Roxo, intitulado "A credibilidade jornalística como crítica à 'cultura da desinformação': uma contribuição ao debate sobre fake news", o foco, de certo modo, continua sobre o impacto e desafios que as mídias digitais têm provocado na configuração social. Aqui, as discussões envolvem um dos aspectos constitutivos e legitimadores do papel do Jornalismo na sociedade: a credibilidade. Isto é, as óbvias (hoje) distorções que a recorrência ao fake news trazem ao campo da informação e comunicação, carregam em seu bojo não só uma " cultura da desinformação" (conforme os autores), como incluem neste percurso a desqualificação do Jornalismo, algo que deve ser discutido em profundidade e sobre vários ângulos (e, quiçá, revertido).

A disposição ao questionamento dos caminhos da comunicação e informação estruturam o próximo texto da Seção Livre, de autoria de Ana Lúcia Nunes de Souza, cujo título é "Videoactivismo: revisión conceptual y práctica del fenómeno". No artigo, a autora apresenta uma revisão conceitual e também um panorama das diversas formas 
de videoativismo, pautadas, em especial, por suas práticas em cenários politicamente tensionados, confirmando amplas e substantivas variações dessas ações constituídas a partir da disposição à luta política. E, visando contribuir com discussões ainda mais próximas ao cotidiano do videoativismo, oferece uma investigação participativa desenvolvida no Rio de Janeiro, reconhecendo que o investimento nesta produção audiovisual tão delimitada por seus pressupostos de enfrentamento, resulta em uma das opções mais férteis e acionadas pelos atuais movimentos sociais.

Das lutas da sociedade civil às institucionais, aquelas que hoje, infelizmente, encontram-se fragilizadas pelo afrouxamento (digamos assim) das políticas públicas cosntruídas com muitos embates e participações populares nos últimos anos no Brasil. Por isso mesmo, é fundamental acompanharmos a atuação dos governos, em especial na sensível e necessária área da Saúde. É o que fazem Kristianne Maia Moreira, Cláudio Márcio Magalhães, Cláudia Chaves Fonseca e Victor Aleves de Almeida Soares que focam nos posicionamentos na internet do Ministério da Saúde na campanha de combate ao mosquito Aedes aegypti. O estudo é comparativo com a literatura e os resultados dessa metodologia de análise apontam para uma necessária revisão da estratégia de comunicação do Ministério.

E, finalmente, fechando a Seção, apresentamos o artigo "Guerra e amizade: o movimento pendular bala-búzio no curta metragem de José Luiz Sol de Varvalho, de autoria de Anna Paula Soares Lemos e Joaquim Humberto Coelho de Oliveira. O artigo se debruça sobre o filme do cineasta moçambicano, observando, em especial, como "as transfigurações movidas pelo princípio da guerra deslocam o cenário do local e do tempo históricos e o transportam para o comum das experiências humanas". Tal diagnóstico tece, alinhado a outras percepções potentes sobre o filme e os embaralhamentos sócio-culturais que este promove, um horizonte que revela $\mathrm{o}$ aprisionamento em um presente que não se esgota, impedindo, assim, de um futuro existir. Um paralelo que, sabemos, pode ser facilmente acionado quando pensamos no Brasil atual.

Boa leitura a todos! 